\title{
Seasonal changes in diurnal rainfall cycle over and around the Indochina Peninsula observed by TRMM-PR
}

\author{
H. G. Takahashi ${ }^{1,2}$ \\ ${ }^{1}$ Japan Agency for Marine-Earth Science and Technology (JAMSTEC), Kanagawa, Japan \\ ${ }^{2}$ Graduate School of Urban Environmental Sciences, Tokyo Metropolitan University (TMU), Tokyo, Japan
}

Received: 15 October 2009 - Revised: 16 February 2010 - Accepted: 16 February 2010 - Published: 8 March 2010

\begin{abstract}
This study used TRMM-PR data to examine seasonal changes in rainfall characteristics over the Indochina Peninsula, with a focus on the diurnal rainfall cycle. No distinct seasonal changes in the phases of diurnal variations of rainfall were found, even though low-level wind fields changed largely with the seasonal march. Regions with an afternoon maximum received large amounts of rainfall during the pre-monsoon season, whereas regions with a nocturnal or morning rainfall maximum received little rainfall during the pre-monsoon season. This result suggests that the difference in diurnal rainfall variations may be associated with the regional differences in seasonal march of monsoon rainfall over and around the Indochina Peninsula, through the different mechanism between evening and morning rainfalls.
\end{abstract}

\section{Introduction}

The diurnal cycle of precipitation is an essential component of the tropical climate. Over the tropics, the diurnal cycle of precipitation is climatologically dominant during the summer monsoon season. Long-term observations by the Tropical Rainfall Measuring Mission-Precipitation Radar (TRMM-PR) allow for climatological examinations of the diurnal precipitation cycle over the entire tropical region, including areas with sparse observation networks.

Over the past three decades, infrared radiation and gaugeobserved rainfall data have been used to examine the diurnal variations of convective activities over the Southeast Asian monsoon region (e.g., Murakami, 1983; Nitta and Sekine, 1994). Pronounced diurnal variations of convective activities during the Asian summer monsoon season were found over the Indochina Peninsula, Tibetan Plateau, Bay of Ben-

Correspondence to: H. G. Takahashi

(hiroshi3@tmu.ac.jp) gal, and South China Sea (Nitta and Sekine, 1994). Hirose and Nakamura (2005) used 6-year TRMM-PR data to show typical diurnal patterns of rainfall over the whole Asian monsoon region, including an evening maximum over land and an early morning maximum around coastal areas. Recently, TRMM-PR data were also used to examine the diurnal cycle of precipitation over the Indochina Peninsula as associated with terrain (Takahashi et al., 2010a).

Seasonal changes in rainfall and related atmospheric fields have also been investigated. Previous studies showed that precipitation during the first half of the summer monsoon season (around June to July) was associated with abundant water vapor transportation by the low-level monsoon southwesterly (Takahashi and Yasunari, 2006), whereas that during the second half of the monsoon season (around August and September) was associated with westward propagating tropical disturbances (Takahashi and Yasunari, 2006, 2008; Takahashi et al., 2009). Matsumoto (1997) described precipitation over the inland area of the Indochina Peninsula during the pre-monsoon season. Later, Kodama et al. (2005) discussed large-scale seasonal changes in precipitation, such as the increase in precipitation during the pre-monsoon season over land and the onset of precipitation over the sea in the beginning of the summer monsoon season.

However, although seasonal changes in rainfall over the Indochina Peninsula have been noted, previous studies did not examine the seasonal changes in the diurnal precipitation cycle. This study describes the seasonal changes of the diurnal precipitation cycle over the Indochina Peninsula. In this note, we focus on the pre-monsoon season and the first and second halves of the monsoon season. Environmental conditions, such as the amount of precipitable water and the land surface condition, may significantly affect precipitation characteristics.

Published by Copernicus Publications on behalf of the European Geosciences Union. 


\section{Data and method}

We used the TRMM-PR rainfall 3G68 product version 6 , which is a gridded version of the TRMM-PR rainfall $2 \mathrm{~A} 25$ product (Iguchi et al., 2000). Hereafter, we refer to these rainfall data as TRMM-PR. The $3 \mathrm{G} 68$ product includes the grid-averaged hourly rainfall amount, the grid-accumulated number of rainfall pixels, and the grid-accumulated total number of observed pixels every hour. These data have a $0.5 \times 0.5^{\circ}$ grid resolution within the tropics and subtropics (approximately $36.5^{\circ} \mathrm{S}-36.5^{\circ} \mathrm{N}$ ). We used 10 years of TRMM-PR observations spanning from 1998 to 2007. To understand the characteristics of the diurnal rainfall cycle and the spatial distribution of rainfall totals, we defined rainfall frequency and rainfall intensity. All three parameters were calculated from the gridded data (3G68). In addition, these parameters were calculated for each hourly time slot. Rainfall amount was calculated as the total rainfall amount for 10 years divided by the total number of observations. Rainfall frequency was given as the number of rainfall pixels divided by the total number of observed pixels by TRMM-PR, given as a percentage. A rainfall pixel was identified when the 2A25 algorithm judged the existence of near-surface rainfall. The rainfall intensity was calculated as the mean rainfall amount divided by the rainfall frequency. Because the study area was limited to the Indochina Peninsula, we used unified local time along $105^{\circ} \mathrm{E}$. Figure 1 shows the study area and its terrain.

In addition, we used monthly mean horizontal winds at $850 \mathrm{hPa}$, from the Japanese 25 -year Reanalysis Project (JRA25; Onogi et al., 2007) data, to capture the seasonal changes in low-level winds. JRA25 data for the Indochina Peninsula were taken from the 27 year period spanning from 1979 to 2005.

To describe seasonal changes in spatial pattern of rainfall associated with diurnal rainfall cycle, we defined two parameters, namely a rainfall ratio and a contribution rate of evening rainfall. The rainfall ratio was defined as the proportions of monthly rainfall amounts during two-month periods [April and May (AM), June and July (JJ), August and September (AS)] to the monthly rainfall amount during the whole rainy season, that is, over six months (from April to September). The rainfall amounts of AM, JJ, and AS were divided by 2 months, and the rainfall amount for the 6 months (from April to September) was divided by 6 months. Both are given in millimeters per month. The rainfall ratio is shown as a percentage, with $100 \%$ indicating that the 2 -month averaged rainfall amount during a period was equivalent to the monthly-averaged rainfall amount during the whole rainy season. The AM, JJ, and AS periods were considered to generally represent the pre-monsoon season, the first half of the summer monsoon, and the second half of the summer monsoon, respectively. Also, the contribution rate of evening rainfall was defined as the proportion of evening rainfall dur-

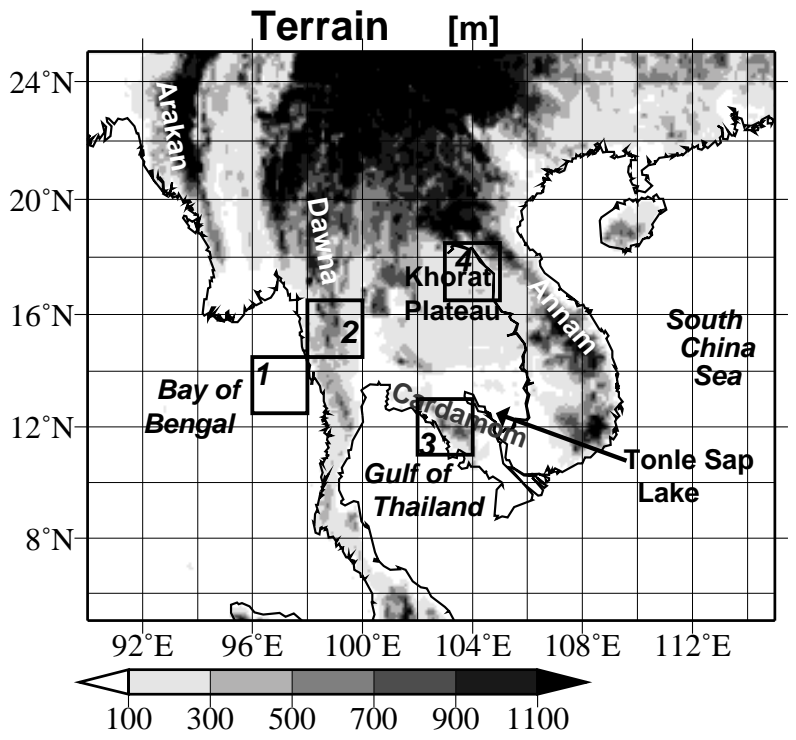

Fig. 1. Terrain elevation and geography of the study area. The gray shade indicates terrain elevation. The rectangles with number (one to four) are the averaged area in Fig. 3.

ing a 12-h period from 13 local time (LT) to $01 \mathrm{LT}$ to the total rainfall amount over $24 \mathrm{~h}$.

\section{Results}

\subsection{Seasonal changes in rainfall amount associated with diurnal rainfall variations}

To understand the seasonal changes in precipitation characteristics associated with diurnal rainfall cycle, we mapped the rainfall ratio, the contribution rate of evening rainfall, and the low-level winds in Fig. 2.

In AM, a large rainfall ratio, equivalent to or more than the rainfall amount for the whole rainy season (over the 6 months from April to September), was observed over inland on the Indochina Peninsula. In the pre-monsoon season, the mountains and surrounding areas received abundant rainfall equivalent to the monsoon season. In these regions, distinct evening rainfall was observed (Fig. 2d), while the regions with morning rainfall have less rainfall in the pre-monsoon season, compared with that in the monsoon season.

In JJ, rainfall amounts drastically changed over the Bay of Bengal and over land on the western (windward) sides of mountain ranges. Land regions with small rainfall ratio during AM, such as the western sides of the Dawna and Annam mountain ranges, and Cardamom mountains, showed increased rainfall amounts in JJ. The regions of the increased rainfall in JJ (Fig. 2b) and morning rainfall (Fig. 2e) basically coincide. Note that rainfall also increased over the Khorat Plateau and around Tonle Sap and the Cardamom mountains; 
(a) Rainfall Ratio, AM

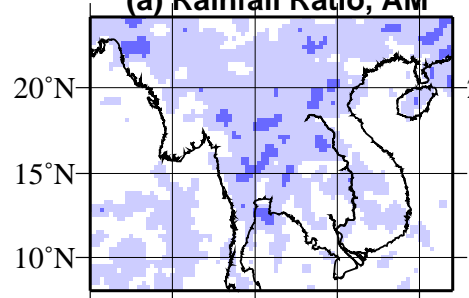

(b) Rainfall Ratio, JJ

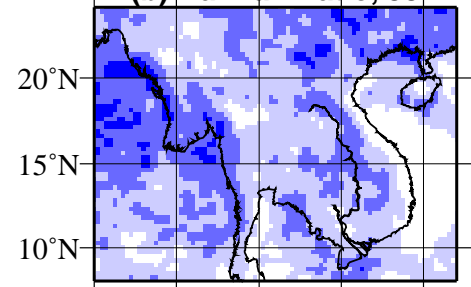

(c) Rainfall Ratio, AS

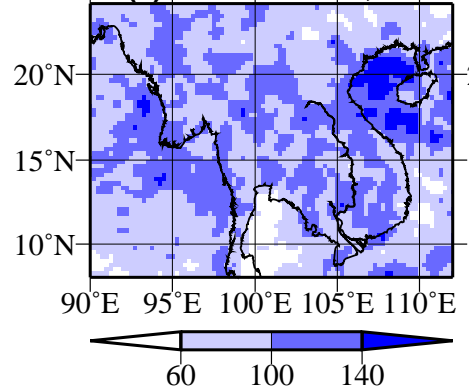

(d) Evening rain, AM

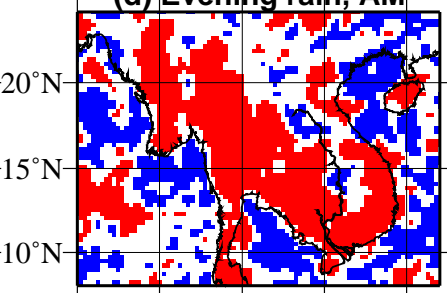

(e) Evening rain, JJ

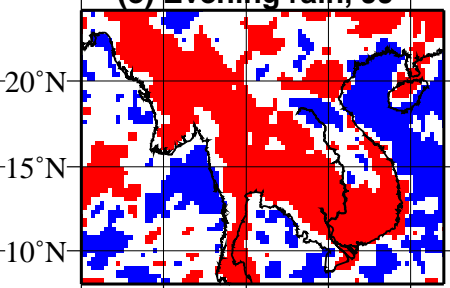

(f) Evening rain, AS

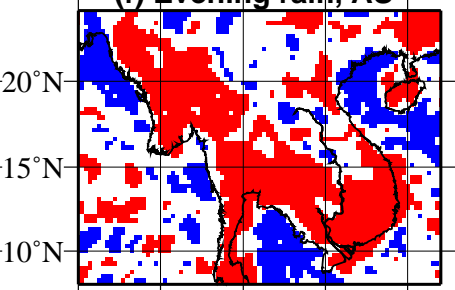

$90^{\circ} \mathrm{E} \quad 95^{\circ} \mathrm{E} \quad 100^{\circ} \mathrm{E} 105^{\circ} \mathrm{E} 110^{\circ} \mathrm{E}$

$\longrightarrow$

$40 \quad 60$

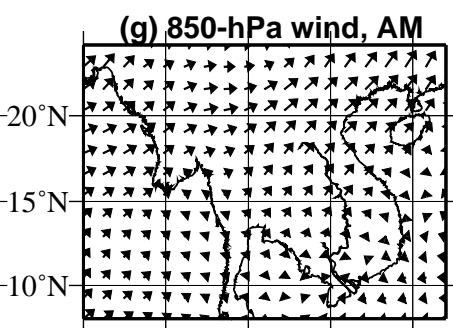

(h) 850-hPa wind, JJ

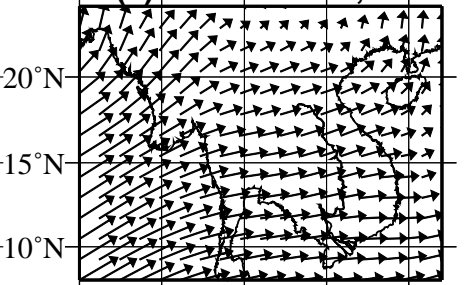

(i) $850-\mathrm{hPa}$ wind, AS

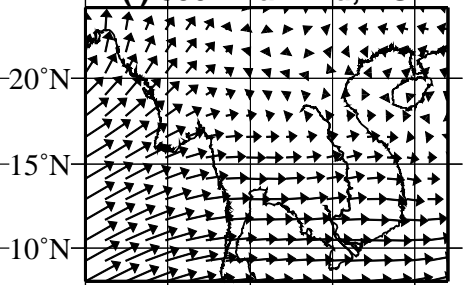

$90^{\circ} \mathrm{E} \quad 95^{\circ} \mathrm{E} 100^{\circ} \mathrm{E} 105^{\circ} \mathrm{E} 110^{\circ} \mathrm{E}$

Fig. 2. The rainfall ratio (a-c), the contribution rate of evening rainfall (d-f), and the low-level winds (g-i) during AM (April and May), JJ (June and July), and AS (August and September). The definitions of the rainfall ratio, and contribution rate of evening rainfall are given in Sect. 2. In (d), (e), and (f), blue (red) color indicates a region that evening rainfall is larger (smaller) than morning rainfall.

these increases were not solely explained by the increase in rainfall over the windward sides of mountain ranges due to the onset of low-level monsoon westerlies (Fig. $2 \mathrm{~g}$ and $\mathrm{h}$ ).

In AS, rainfall amounts increased substantially over the South China Sea. This increase in rainfall amount has been associated with tropical disturbance activity (Takahashi and Yasunari, 2008). High rainfall amounts were also observed over basin-shaped plains having no obstacles in the southern direction. In these regions, much water vapor may be supplied immediately after the passage of tropical disturbances. This result supports the previous result that tropical cyclones are a major contributor to rainfall over the Indochina Peninsula during the second half of the summer monsoon season.

Therefore, significant evening rainfall was observed from the pre-monsoon to monsoon seasons over inland regions, such as on the eastern side of the Dawna mountain ranges, the north of the Khorat Plateau, over the Cardamom mountains, and around Arakan mountains, whereas morning rainfall was large only in the monsoon season. Interestingly, the spatial patterns of the contribution rates of evening rainfall to the total rainfall did not show seasonal variation, even if low-level monsoon westerlies largely change. This result suggests that the seasonal changes in diurnal phase of rainfall is not noticeable. Note also that the high-resolution data used in this study could show the detailed seasonal changes in precipitation associated with diurnal rainfall variations.

\subsection{Seasonal changes in the diurnal precipitation cycle}

To understand the seasonal changes in precipitation characteristics with a focus on the diurnal precipitation cycle, we plotted the diurnal cycles of rainfall amount, rainfall frequency, and rainfall intensity during $\mathrm{AM}, \mathrm{JJ}$, and $\mathrm{AS}$ in Fig. 3. In Fig. 1, the four regions are shown as open rectangles, which were chosen in terms of diurnal variations of rainfall. Region 1 is located over the eastern Bay of Bengal near the coast, an area that receives morning rainfall. Region 2 is around the mountain ranges of the western Indochina Peninsula, which is characterized as evening rainfall region. Region 3 is located over and around the Cardamom mountains, which includes both evening and morning rainfall regions. The two peaks in rainfall were discussed by Takahashi et al. (2010a). Region 4 includes the eastern Khorat Plateau. This region has morning rainfall. The land-surface 
(a) Diurnal Cycle of Rainfall Amount [mm/hr]
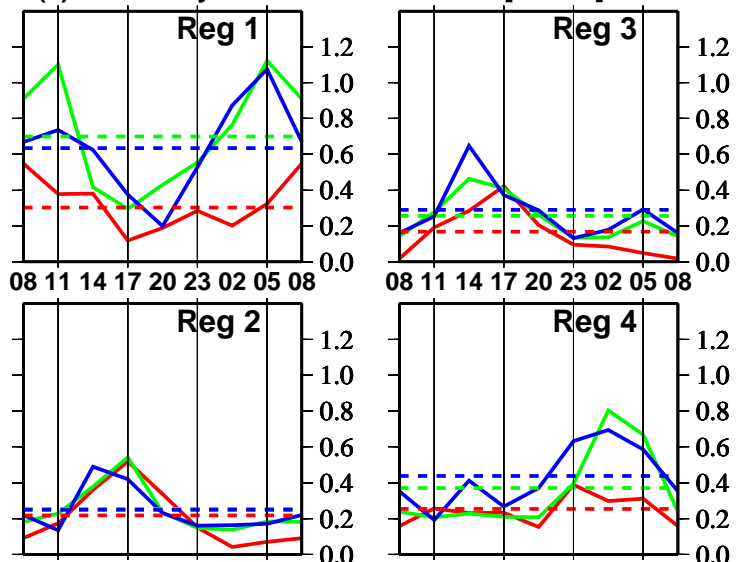

081114172023020508

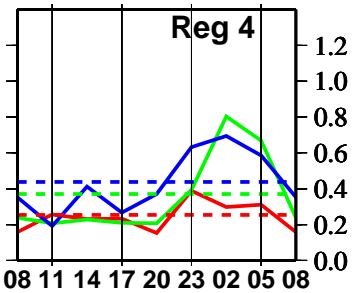

(b) Diurnal Cycle of Rainfall Frequency [\%]
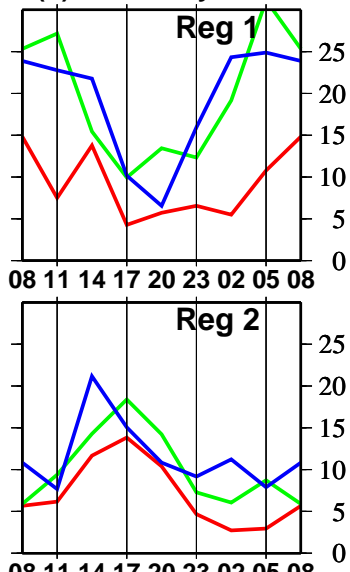

081114172023020508
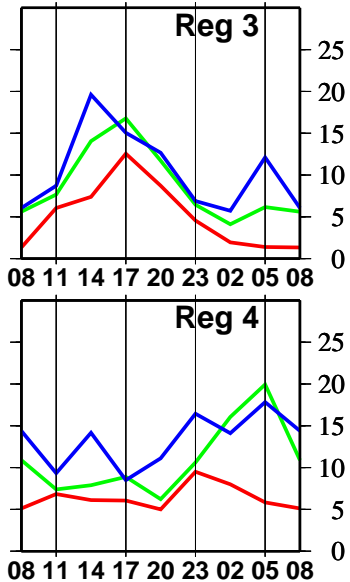

(c) Diurnal Cycle of Rainfall Intensity [ $\mathrm{mm} / \mathrm{hr}]$
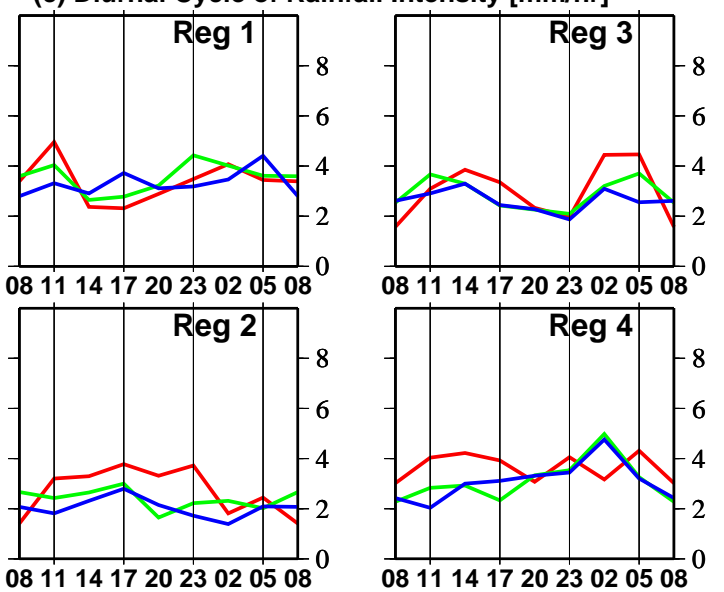

Fig. 3. Diurnal cycle in rainfall amount (a), rainfall frequency (b), and rainfall intensity (c) over the four regions. The region was shown in Fig. 1. The Red lines denote that during AM. Green lines show that during JJ, and blue lines indicate that during AS. The dashed lines in (a) indicate the daily mean value of rainfall amount during each period. properties are different between Regions 1 and 4, although they both have distinct morning rainfall. From these four regions, we can find out the seasonal changes in rainfall characteristics associated with the different diurnal cycle of rainfall. 3-h averages for rainfall amount, rainfall frequency, and rainfall intensity during each period are shown in Fig. 3. Also, these values of the regions were averaged for each twodegree box.

Most of the regions showed clear diurnal variations in rainfall amount during the whole summer monsoon season (Fig. 3a). Regions 1 and 4 had significant nocturnal or morning maxima in rainfall amount, whereas Region 2 had distinct maximum in early afternoon. Region 3 has two peaks within the diurnal rainfall cycle, because it includes both evening and morning rainfall regions. No distinct seasonal changes in the phases of diurnal variations in rainfall amount over all four regions were observed, even though low-level wind fields changed largely (Fig. 2g, h, and i). As mentioned above, distinct seasonal changes in rainfall amount from AM to JJ were found over Regions 1 and 4, with an extension of the hours of high rainfall in those regions with the seasonal march. The seasonal changes in rainfall frequency play a major role in the seasonal changes in rainfall amount over Regions 1 and 4, as seasonal changes in rainfall intensity are unclear. Over Regions 2, no significant seasonal change was found in rainfall amount. Furthermore, seasonal change in rainfall amount was found not in evening hours but in morning hours over Region 3. Over Regions 2 and 3, rainfall frequencies in $\mathrm{AM}$ are lower than those in $\mathrm{JJ}$ and $\mathrm{AS}$, while rainfall intensities in AM are somewhat stronger than those in JJ and AS. The results of the two regions with the early afternoon rainfall maximum indicate that the rainfall activity starts from the pre-monsoon season over the regions.

Note that diurnal rainfall variations over the four regions were dominant, even though the rainfall activity during AS was associated with tropical cyclone activity. These dominant diurnal variations in rainfall during the whole summer monsoon season indicate that the processes of each rainfall event are associated with the development of the diurnally synchronized rainfall systems. Thus, this study shows that regions with similar diurnal variations in rainfall have similar seasonal variations in rainfall throughout the Southeast Asian summer monsoon.

\section{Discussion}

In terms of diurnal precipitation cycles over land on the Indochina Peninsula, the regions with the afternoon maximum in rainfall received large amounts of rainfall during the premonsoon season, whereas the regions with the nocturnal or morning maximum received little rainfall during the premonsoon season. This result suggests that the regional difference in the diurnal maximum of rainfall is likely related to the regional difference of onset of monsoon rainfall over and 
around the Indochina Peninsula. In general, the afternoon maximum of precipitation is probably associated with the increase in water vapor and the convergence of winds over the mountain ranges due to thermally-induced local circulations (e.g., Takahashi et al., 2010b). As a mechanism of nocturnal rainfall, Satomura (2000) proposed the leeward propagation of rainfall systems using a two-dimensional numerical model. Hirose and Nakamura (2005) reported that nocturnal precipitation consisted of large-scale rainfall systems that could be distinguished from afternoon rainfall systems. A recent three-dimensional high-resolution modeling study also showed that the gravity-current-like flow from rainfall activity over mountain ranges can trigger nocturnal rainfall systems over the Indochina Peninsula (Takahashi et al., 2010b). However, the mechanisms of nocturnal and morning rainfall systems over the Indochina Peninsula have been unclear.

What induces early afternoon rainfall during the premonsoon season? Takahashi et al. (2010b) demonstrated that drier surface conditions induced stronger diurnal variations in precipitable water associated with enhanced local circulations over the Indochina Peninsula. Fujita et al. (2006) also showed that a drier surface condition induced stronger local circulation, resulting in a larger diurnal range of precipitable water. Hence, a drier surface condition likely enhances the convergence of water vapor and winds around the mountain ranges through the intensification of local circulations. These results suggest that efficient water vapor transport to the mountain ranges can occur in the pre-monsoon season, resulting in abundant amounts of rainfall.

The proposed mechanisms of nocturnal and morning rainfall are explained as triggering by a gravity current from rainfall systems. This mechanism may require much water vapor in the lower troposphere for the onset and sequential development of rainfall systems, although water vapor amounts over the Indochina Peninsula are not as large in the pre-monsoon season as in the monsoon season. These different characteristics between early afternoon and nocturnal rainfalls may explain the different seasonal changes.

\section{Conclusions}

This note has described seasonal changes in rainfall characteristics over the Indochina Peninsula, focusing on the diurnal rainfall cycle, as shown by TRMM-PR data. We divided the rainy period of the summer monsoon season into three sub-periods: the pre-monsoon season and the first and second halves of the Indochina monsoon season.

In the pre-monsoon season, abundant rainfall equivalent to that of the whole rainy season (from April to September) was observed over inland on the Indochina Peninsula. During AM, high rainfall over the Indochina landmass occurred in regions having an afternoon maximum of rainfall, whereas land regions with nocturnal or morning maximum rainfall had low rainfall during AM. The coastal regions near the land with a morning maximum also have little rainfall during AM. These regions with morning maximum of rainfall showed large increases in rainfall from AM to JJ. The distribution of rainfall amount during AS was probably associated with tropical cyclone activity, as high rainfall amounts were observed over plains having no obstacles in the southern direction.

Another interesting finding is that diurnal rainfall variations are dominant during the whole summer monsoon season. In addition, the absence of distinct seasonal changes in the phases of diurnal variations in rainfall was found, even though the low-level wind fields changed largely with the seasonal march. In addition, no distinct seasonal changes in rainfall intensity were observed, compared with the seasonal changes in rainfall frequency. Over the region with nocturnal and morning rainfall, the seasonal changes in precipitation amount were caused by an extension of the major rainfall hours.

Therefore, the diurnal rainfall variations are probably associated with the seasonal march of rainfall, particularly in the onset phase of the rainy season.

Acknowledgements. TRMM-PR rainfall data (3G68 product) were obtained from ftp://trmmopen.gsfc.nasa.gov/pub/3G68 via FTP. The author thanks two anonymous reviewers for their helpful suggestions and comments.

Edited by: S. C. Michaelides

Reviewed by: two anonymous referees

\section{References}

Fujita, M., Sasaki, T., and Kimura, F.: A dramatic daytime decrease in water vapor over coastal Thailand, SOLA, 2, 49-52, 2006.

Hirose, M. and Nakamura, K.: Spatial and diurnal variation of precipitation systems over Asia observed by the TRMM Precipitation Radar, J. Geophys. Res., 110, D05106, doi:10.1029/2004JD004815, 2005.

Iguchi, T., Kozu, T., Meneghini, R., Awaka, J., and Okamoto, K.: Rain-profiling algorithm for the TRMM Precipitation Radar, J. Appl. Meteorol., 39, 2038-2052, 2000.

Kodama, Y., Ohta, A., Katsumata, M., Mori, S., Satoh, S., and Ueda, H.: Seasonal transition of predominant precipitation type and lightning activity over tropical monsoon areas derived from TRMM observations, Geophys. Res. Lett, 32, doi:10.1029/2005GL022986, 2005.

Matsumoto, J.: Seasonal transition of summer rainy season over indochina and adjacent monsoon region, Adv. Atmos. Sci., 14, 231-245, 1997.

Murakami, M.: Analysis of the deep convective activity over the western Pacific and Southeast Asia. Part I: Diurnal variation, Journal of the Meteorological Society of Japan, 61, 60-76, 1983.

Nitta, T. and Sekine, S.: Diurnal variation of convective activity over the tropical western Pacific, Journal of the Meteorological Society of Japan, 72, 627-641, 1994. 
Onogi, K. et al.: The JRA-25 Reanalysis, Journal of the Meteorological Society of Japan, 85, 369-432, 2007.

Satomura, T.: Diurnal variation of precipitation over the Indo-China Peninsula: Two-dimensional numerical simulation, Journal of the Meteorological Society of Japan, 78, 461-475, 2000.

Takahashi, H. and Yasunari, T.: A climatological monsoon break in rainfall over Indochina -A singularity in the seasonal march of the Asian summer monsoon-, J. Climate, 19, 1545-1556, 2006.

Takahashi, H. and Yasunari, T.: Decreasing trend in rainfall over Indochina during the late summer monsoon: Impact of tropical cyclones, Journal of the Meteorological Society of Japan, 86, 429-438, 2008.
Takahashi, H., Yoshikane, T., Hara, M., and Yasunari, T.: Highresolution regional climate simulations of the long-term decrease in September rainfall over Indochina, Atmos. Sci. Lett., 10(1), 14-18, doi:10.1002/asl.203, 2009.

Takahashi, H., Fujinami, H., Yasunari, T., and Matsumoto, J.: Diurnal rainfall pattern observed by TRMM-PR around the Indochina Peninsula, J. Geophys. Res., 115, doi:10.1029/2009JD012155, 2010a.

Takahashi, H., Yoshikane, T., Hara, M., Takata, K., and Yasunari, T.: High-resolution modelling of the potential impact of land-surface conditions on regional climate over Indochina associated with the diurnal precipitation cycle, Int. J. Climatol., doi:10.1002/joc.2119, 2010 b. 